Research Paper

\title{
The Simplified Edinburgh Postnatal Depression Scale (EPDS) for Antenatal Depression: Is It a Valid Measure for Pre-Screening?
}

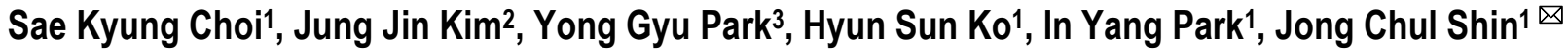

1. Department of Obstetrics and Gynecology, College of Medicine, Catholic University of Korea.

2. Department of Psychiatry, College of Medicine, Catholic University of Korea.

3. Department of Biostatistics, College of Medicine, Catholic University of Korea.

$\triangle$ Corresponding author: Jong Chul Shin, MD. Department of Obstetrics and Gynecology, College of Medicine, Catholic University of Korea, 505 Banpo-dong, Seocho-gu, Seoul 137-040, Korea. E-mail: jcshin@catholic.ac.kr; Phone: 82-2-2258-2813; Fax: 82-2-595-1549.

() Ivyspring International Publisher. This is an open-access article distributed under the terms of the Creative Commons License (http://creativecommons.org/ licenses/by-nc-nd/3.0/). Reproduction is permitted for personal, noncommercial use, provided that the article is in whole, unmodified, and properly cited.

Received: 2011.09.09; Accepted: 2011.11.07; Published: 2011.11.17

\begin{abstract}
The identification of antenatal depression is critical but poorly conducted. The aim of this study was to construct a simplified depression survey scale and to verify its efficacy as a pre-screening for antenatal depression. A total of 494 pregnant women in the third trimester of gestation who had received antenatal care at Seoul St. Mary's Hospital from July 2009 to June 2010 were included. The Edinburgh Postnatal Depression Scale (EPDS) questionnaire was completed by them. The subjects were randomly divided into two groups: 250 of training set and 244 of validation set. We designed a simplified questionnaire comprising two items of EPDS using the training set. We then validated its efficacy with the training set and reaffirmed the results with the validation set. The sum of item 5 (scare or panic) and item 8 (sadness or misery) explained $75.5 \%$ of the total score of the EPDS (AUC $=0.947$ ). Using a score of 3 as a cut-off value of the simplified scale, sensitivity was $92.4 \%$ and specificity was $86.3 \%$. The positive and negative predictive values were $56.2 \%$ and $98.4 \%$, retrospectively. This study suggests that the simplified EPDS can be an efficient instrument to rule out depression during pregnancy.
\end{abstract}

Key words: Antenatal depression, Edinburgh Postnatal Depression Scale, Screening, Perinatal mental health, Depression.

\section{Introduction}

Many women experience physiological and social changes related to pregnancy and want to adapt to these changes. However, changing circumstances without preparation can cause mental and emotional problems, and the influence of hormones associated with pregnancy can aggravate the occurrence of these problems. For these reasons, women of childbearing age can be at high risk for depressive disorder (1).

Perinatal mental disorder is characterized by depression, anxiety, or somatic symptoms that occur during the antenatal and postnatal periods. However, postpartum depression is the only perinatal mental disorder that has been the focus of extensive studies
$(2,3)$. It has only been during the last decade that a shift from the narrow concept of postpartum depression to a consideration of the spectrum of depressive symptoms arising throughout the perinatal period has been observed (4).

Antenatal depression is a nonpsychotic depressive episode that begins during pregnancy. It is as common as postpartum depression, but less documented (5). Some studies have found that the incidence of depression is similar during the antenatal and postnatal periods $(6,7)$. Other studies suggest that antenatal depression may be more prevalent than postpartum depression and that the incidence of an- 
tenatal depression is as high as $20 \%$, twice as frequent as the reported rate of $11 \%$ for postpartum depression (8-10).

Antenatal depression had been identified as a risk factor for postpartum depression and for adverse obstetric and neonatal outcomes (11-13). Neonatal adverse outcomes include preterm labour, low birth weight, and neonatal complications associated with increased morbidity and mortality in the infant (14-17). Untreated antenatal depression has also been associated with smaller head circumference, lower Apgar scores, higher cortisol levels at birth, alteration in heart rate variability, and increased admissions to neonatal care units (18-20). Moreover, adverse long-term effects on early child development may be associated with depressive symptoms during pregnancy (21).

Only a minority of pregnant women suffering from depression are identified by health care providers despite its importance (22-24). A major impediment to depression detection is the difficulty in the administration of depression screening tests in busy clinical settings (25). The instruments for screening depression can be used during pregnancy and the postpartum period, but they generally require at least 5 minutes to complete and even longer to interpret.

If there were simplified screening instruments, obstetrical health care providers would be able to identify the women who have depressive symptoms easier. Therefore, the purposes of our study are: (1) to design a simplified depression scale that is easy to administer in the clinic and (2) to assess the validity of the newly developed instrument as a pre-screen for antenatal depression.

\section{Methods}

\section{Study population}

All pregnant women in the third trimester of gestation who had received antenatal care at Seoul St. Mary's Hospital from July 2009 to June 2010 were asked to participate in this prospective study. The aims and procedures of the study were explained to the women when they visited the hospital for antenatal care. A total of 494 pregnant women who provided consent were included in the study, and written consent was obtained. Women who did not speak Korean or had missing depression screening data were excluded. The Korean version of the Edinburgh Postnatal Depression Scale (EPDS) was completed while the women were waiting for their prenatal medical appointment, and all were scored by one researcher. Participants also completed a questionnaire that recorded their socio-demographic factors and obstetrical characteristics. The socio-demographic and obstetrical risk factors questionnaire included questions on age, pregestational body mass index (BMI), parity, gestational age, highest level of education completed, occupation, alcohol and smoking habits, past and/or current health problems, and past history of adverse obstetrical outcomes such as abortion or preterm delivery. The study was approved by the Ethics Committees at the Clinical Research Coordinating Center of the Catholic Medical Center (KC09OIS01368).

\section{Measures of depressive symptoms}

Depressive symptoms were measured using the EPDS, a 10-item self-report scale. This instrument was designed by Cox et al. to screen for postpartum depression (26). It is the most widely used screening questionnaire for postpartum depression (27), and has been widely validated for not only this condition but also antenatal depression $(28,29)$. In addition, it is the only rating scale for depression that has been validated as applicable to the antenatal period(30). For each item, women are asked to select one of four responses that most closely describe how they have felt over the past 7 days. Each response has a value between 0 and 3; scores for the 10 items are summed to give a total score between 0 and 30 . We chose to regard an EPDS score $\geq 12$ as indicating depression. Although a number of cut-off points have been used, sensitivity for the identification of major depression in pregnancy has been found to be $>95 \%$ with a specificity of $>95 \%$ at this cut-off point (31). Cronbach's alpha coefficient of the EPDS in this study was 0.82 .

\section{Statistical analysis}

The subjects were randomly divided into two groups: 250 of training set and 244 of validation set. We analyzed the relationships between each item or subset of items and the total EPDS score for the training data set. Within the two groups, the number of women found to be depressive by the EPDS was approximately equal; that is, 38 in the training set and 41 in the validation set. To determine the items and groups of items that best predicted the total EPDS score, Pearson correlation analysis and multiple linear regression with best subset selection options were performed, and the coefficients of determination were used for selecting the reduced set of items.

We chose the cut-off point and evaluated the screening performance of the simplified EPDS by receiver-operating characteristic (ROC) curve analysis. We present here the resulting sensitivity, specificity, positive predictive value, negative predictive value, and the area under the curve (AUC) and correspond- 
ing $95 \%$ confidence intervals (CIs) for the determined cut-off value.

To confirm the validity of results obtained from the training data set, we applied the same procedures to the validation data set and total data set. Statistical analysis of the socio-demographic and obstetrical data was carried out using Student's $t$-test and Fisher's exact test. SAS version 9.1 software (SAS Institute, Cary, NC, USA) was used for all statistical analyses. All tests were two-tailed, and a $P$ value $<0.05$ was regarded as statistically significant.

\section{Results}

\section{Characteristics of study population}

A total of 494 pregnant women joined the study and completed the questionnaire. Table 1 presents the socio-demographic characteristics of the participants. Overall, the participants comprised primarily highly educated women with demographic characteristics consistent with that background. More than half of the participants were between the ages of 30 and 35 . The proportion of primipara and multipara was similar. The scores of 79 of 494 women were $\geq 12$ points, which is the cut-off value to define depressive symptoms by EPDS. The distribution of demographic variables did not vary significantly between the two groups, 'depressed' and 'not depressed'. Only occupational status was significantly associated with a positive EPDS screen $(P=0.038)$.

The total EPDS score averages were $7.38 \pm 4.27$ in the whole study population, $14.7 \pm 2.75$ in the depressed group, and $5.98 \pm 2.84$ in the not depressed group $(P<0.0001)$. The scores of all items showed a significant difference between the two groups $(P<$ 0.0001). Items that obtained high scores in both groups were item 3 (self-blame), item 4 (anxiety or worry), and item 5 (scare or panic). Item 8 (sadness or misery) was scored high in the depressed group (Table 2).

Table I. Demographic characteristics of study population.

\begin{tabular}{|c|c|c|c|}
\hline & Depressed $(n=79)$ & Not depressed $(n=415)$ & $P$ value* \\
\hline Age (yr) & $32.6 \pm 4.08$ & $32.3 \pm 3.60$ & 0.460 \\
\hline Pregestational BMI (kg/m²) & $21.1 \pm 2.95$ & $20.7 \pm 2.69$ & 0.189 \\
\hline Parity & & & 0.386 \\
\hline Primipara & $42(53.2)$ & $248(59.9)$ & \\
\hline Multipara & $37(46.8)$ & $167(40.2)$ & \\
\hline Gestational age (wk) & $33.7 \pm 3.35$ & $33.8 \pm 3.57$ & 0.940 \\
\hline Education & & & 0.271 \\
\hline Less than high school & $0(0.0)$ & $1(0.2)$ & \\
\hline High school graduate & $11(14.1)$ & $35(8.5)$ & \\
\hline College graduate & $67(85.9)$ & 377 (91.3) & \\
\hline Occupation & & & 0.038 \\
\hline Not employed & $14(17.7)$ & $74(17.9)$ & \\
\hline Quit after pregnancy & $31(39.2)$ & $106(25.6)$ & \\
\hline Employed & $34(43.0)$ & $234(56.5)$ & \\
\hline Alcohol & & & 0.095 \\
\hline Yes & $2(2.6)$ & $2(0.4)$ & \\
\hline Quit after pregnancy & $41(52.6)$ & $193(46.7)$ & \\
\hline No & $35(44.9)$ & $218(52.8)$ & \\
\hline Smoking & & & 0.344 \\
\hline Yes & $0(0.0)$ & $0(0.0)$ & \\
\hline Quit after pregnancy & $5(6.33)$ & $15(3.6)$ & \\
\hline No & $74(93.7)$ & $399(96.4)$ & \\
\hline Past medical history & & & 0.192 \\
\hline Yes & $18(22.8)$ & $67(16.2)$ & \\
\hline No & $61(77.2)$ & $347(83.8)$ & \\
\hline Psychiatric illness & & & 0.071 \\
\hline Yes & $4(5.1)$ & $5(1.0)$ & \\
\hline No & $75(94.9)$ & $409(98.8)$ & \\
\hline History of abortion & & & 0.066 \\
\hline Yes & $36(45.6)$ & $137(33.0)$ & \\
\hline No & $43(54.4)$ & $278(67.0)$ & \\
\hline History of preterm delivery & & & 1.000 \\
\hline Yes & $3(3.8)$ & $20(4.8)$ & \\
\hline No & $76(96.2)$ & 395 (95.2) & \\
\hline
\end{tabular}

Values are presented as mean $\pm \mathrm{SD}$ or $n(\%)$; BMI, body mass index.

* obtained by $t$-test for continuous and chi-square test or Fisher's exact test for categorical variables. 
Table 2. Distributions of Edinburgh Postnatal Depression Scale (EPDS) items and differences between "depressed" and "not depressed" groups.

\begin{tabular}{|c|c|c|c|}
\hline EPDS item & $\begin{array}{l}\text { Depressed } \\
(n=79)\end{array}$ & $\begin{array}{l}\text { Not depressed } \\
(n=415)\end{array}$ & $P$ value ${ }^{*}$ \\
\hline E1. I have been able to laugh and see the funny side of things & $0.46 \pm 0.57$ & $0.06 \pm 0.24$ & $<0.0001$ \\
\hline E2. I have looked forward with enjoyment to things & $1.16 \pm 0.79$ & $0.39 \pm 0.56$ & $<0.0001$ \\
\hline E3. I have blamed myself unnecessarily when things went wrong & $2.32 \pm 0.61$ & $1.46 \pm 0.79$ & $<0.0001$ \\
\hline E4. I have been anxious or worried for no good reason & $2.22 \pm 0.57$ & $1.44 \pm 0.71$ & $<0.0001$ \\
\hline E5. I have felt scared or panicky for no very good reason & $1.85 \pm 0.77$ & $0.90 \pm 0.74$ & $<0.0001$ \\
\hline E6. Things have been getting on top of me & $1.54 \pm 0.64$ & $0.71 \pm 0.63$ & $<0.0001$ \\
\hline E7. I have been so unhappy that I have had difficulty sleeping & $1.53 \pm 0.68$ & $0.27 \pm 0.54$ & $<0.0001$ \\
\hline E8. I have felt sad or miserable & $1.87 \pm 0.43$ & $0.47 \pm 0.68$ & $<0.0001$ \\
\hline E9. I have been so unhappy that I have been crying & $1.33 \pm 0.75$ & $0.26 \pm 0.53$ & $<0.0001$ \\
\hline E10. The thought of harming myself has occurred to me & $0.43 \pm 0.65$ & $0.04 \pm 0.19$ & $<0.0001$ \\
\hline Total score of EPDS & $14.7 \pm 12.75$ & $5.98 \pm 2.84$ & $<0.0001$ \\
\hline
\end{tabular}

Values are presented as mean $\pm \mathrm{SD}$.

* obtained by $t$-test.

\section{The simplified EPDS}

The simplified EPDS was designed with the training set of 250 samples and then cross-validated with the validation set of 244 samples.

The degree of explanation of each EPDS item for the EPDS total score is shown in Table 3. Each item was highly associated with a positive EPDS screen. Item 8 (sadness or misery) scored the highest correlation. We defined the simplified instrument as the simple sum of items of EPDS. Among two-item subset models, we found that the sum of item 5 (scare or panic) and item 8 (sadness or misery) was the best two-item subset, explaining $75.5 \%$ of the variation of EPDS total score and producing an AUC of $95.5 \%$.

The more items that were added, the better the total score of EPDS was explained. For example, among three-item subset models, we found that the sum of item 5 (scare or panic), item 8 (sadness or misery), and item 4 (anxiety or worry) was the best three-item subset, explaining $81.9 \%$ of the variation of total EPDS with an AUC of $94.8 \%$. However, these results showed that the three-item subset increased the power of explanation but decreased the screening ability, as shown by the AUC, compared with the two-item subset. Therefore, we composed the simplified questionnaire based on the sum of two EPDS items that had high R-squares and AUCs: item 5 (scare or panic) and item 8 (sadness or misery). The sum of these two items was reasonably correlated with the total EPDS score, and the approach was also the simplest in that it used the fewest number of items. The performance of the simplified EPDS against total EPDS score is shown in Table 4. Using the simplified EPDS, the AUC for antenatal depressive symptoms was 0.955 , and a cut-off score of 3 was found to be most suitable for screening of depressive symptoms. When using a score of 3 as a cut-off value of the simplified scale applied to the training set, the sensitivity was 0.921 (95\% CI, 0.835-1.000), the specificity was 0.877 (95\% CI, 0.833-0.922), the positive predictive value was 0.574 (95\% CI, 0.450-0.698), and the negative predictive value was $0.984(95 \% \mathrm{CI}$, 0.966-1.000).

In the validation set, item 8 (sadness or misery) scored the highest correlation, and the sum of item 5 (scare or panic) and item 8 (sadness or misery) explained the total score of EPDS most effectively. Application of the simplified scale produced the same results when applied to the total study population (Table 3). The effectiveness of the simplified EPDS with the validation set and total set are calculated by ROC curve analysis. The AUCs were 0.938 and 0.947, respectively. As a result, we concluded that the newly developed instrument performed well in detecting pregnant women with depressive symptoms. With a cut-off score of 3, the sensitivity was 0.927 (95\% CI, $0.847-1.000)$, the specificity was 0.847 (95\% CI, $0.798-0.897)$, the positive predictive value was 0.551 (95\% CI, 0.433-0.668), and the negative predictive value was 0.983 (95\% CI, 0.964-1.000) in the validation set. In the total study population, the sensitivity was 0.924 (95\% CI, 0.866-0.982), the specificity was 0.863 (95\% CI, 0.830-0.896), the positive predictive value was 0.562 (95\% CI, 0.476-0.647), and the negative predictive value was 0.984 (95\% CI, 0.970-0.997). 
Table 3. Degrees of explanation/discrimination of each item for depression.

\begin{tabular}{|c|c|c|c|c|c|c|}
\hline \multirow[t]{2}{*}{ Item } & \multicolumn{2}{|c|}{$\begin{array}{l}\text { Training set } \\
(n=250)\end{array}$} & \multicolumn{2}{|c|}{$\begin{array}{l}\text { Validation set } \\
(n=244)\end{array}$} & \multicolumn{2}{|c|}{$\begin{array}{l}\text { Total set } \\
(n=494)\end{array}$} \\
\hline & $\mathrm{R}^{2}$ & AUC & $\mathrm{R}^{2}$ & AUC & $\mathrm{R}^{2}$ & AUC \\
\hline E1 & 0.1174 & 0.667 & 0.2159 & 0.692 & 0.1660 & 0.680 \\
\hline E2 & 0.3510 & 0.805 & 0.2414 & 0.738 & 0.2943 & 0.771 \\
\hline E3 & 0.4153 & 0.791 & 0.3304 & 0.763 & 0.3776 & 0.778 \\
\hline E4 & 0.3934 & 0.749 & 0.4304 & 0.800 & 0.4084 & 0.775 \\
\hline E5 & 0.4534 & 0.812 & 0.4010 & 0.766 & 0.4307 & 0.790 \\
\hline E6 & 0.3935 & 0.762 & 0.4593 & 0.834 & 0.4281 & 0.798 \\
\hline E7 & 0.5251 & 0.894 & 0.5284 & 0.890 & 0.5279 & 0.893 \\
\hline E8 & 0.5396 & 0.926 & 0.5877 & 0.916 & 0.5611 & 0.921 \\
\hline E9 & 0.4731 & 0.858 & 0.4704 & 0.843 & 0.4721 & 0.852 \\
\hline E10 & 0.1878 & 0.629 & 0.2634 & 0.687 & 0.2273 & 0.659 \\
\hline $\mathrm{E} 5+\mathrm{E} 8$ & 0.7551 & 0.955 & 0.7538 & 0.938 & 0.7553 & 0.947 \\
\hline $\mathrm{E} 5+\mathrm{E} 8+\mathrm{E} 4$ & 0.8192 & 0.948 & 0.7930 & 0.950 & 0.8062 & 0.950 \\
\hline
\end{tabular}

$\mathrm{R}^{2}$, coefficient of determination; AUC, area under the receiver-operating characteristic curve

Table 4. Diagnostic abilities of the simplified Edinburgh Postnatal Depression Scale (EPDS) score using cut-off value 3.

\begin{tabular}{llll}
\hline Diagnostic values & $\begin{array}{l}\text { Training set } \\
(n=250)\end{array}$ & $\begin{array}{l}\text { Validation set } \\
(n=244)\end{array}$ & $\begin{array}{l}\text { Total set } \\
(n=494)\end{array}$ \\
\hline Sensitivity & $35 / 38(92.1)$ & $38 / 41(92.7)$ & $73 / 79(92.4)$ \\
& $(83.5-100)$ & $(84.7-100)$ & $358-98.2)$ \\
Specificity & $186 / 212(87.7)$ & $172 / 203(84.7)$ & $(83.0-89.6)$ \\
& $(83.3-92.2)$ & $(79.8-89.7)$ & $73 / 130(56.2)$ \\
PPV & $35 / 61(57.4)$ & $38 / 69(55.1)$ & $(47.6-64.7)$ \\
& $(45.0-69.8)$ & $(43.3-66.8)$ & $358 / 364(98.4)$ \\
NPV & $186 / 189(98.4)$ & $172 / 175(98.3)$ & $(97.0-99.7)$ \\
& $(96.6-100)$ & $(96.4-100)$ & $431 / 494(87.2)$ \\
Total accuracy & $221 / 250(88.4)$ & $210 / 244(86.1)$ & $(84.3-90.2)$ \\
\hline
\end{tabular}

Values in the second line are $95 \%$ confidence intervals.

PPV, positive predictive value; NPV, negative predict value.

Values in parentheses are percentages, and $95 \%$ confidence intervals are presented in the

\section{Discussion}

Routine antenatal screening for depression is logical because no pregnant women can be considered risk free (32). For this reason, identification of the pregnant women who have perinatal depressive symptoms is considered a critical goal of the maternal care system (32-36). However, use of the screening survey is impractical in busy clinical settings in Korea because the traditional screening questionnaires require excessive time for interpretation after the pregnant women complete them.

There have already been attempts to simplify the EPDS. Pallant et al. suggested a revised eight item version of EPDS which would show high levels of agreement with the original case identification the EPDS (37). But, the simplified EPDS consisting of 8 items still needs a lot of time to complete. In this study, we determined that pre-screening with a simplified EPDS containing two items generally had good sensitivity and specificity for identifying women that would show positive screening results on the EPDS. In accordance with the ROC results, we recommend using the simplified EPDS with a cut-off score of 3 to detect pregnant women with depressive symptoms. This simple screening procedure takes less time and may be useful as a tool to rule out women who would otherwise require further time-consuming assessment for antenatal depressive symptoms. The use of a brief and general screening test that is quick and easy to administer and score could be utilized for detection of such depressive symptoms by primary health care providers. Identifying perinatal depressive symptoms is important not only for the mother but also for the fetus and newborn. The simplified EPDS may have sufficient accuracy to identify women at 
risk for antenatal depression. A remaining challenge is how to link the many women who screen positive to professional help.

Screening for depression is only meaningful when paired with confirmatory diagnosis and treatment. Goodman et al. reported that detection, treatment, and referral of pregnant women with perinatal depression by obstetrical providers are seriously lacking after analyzing screening results of screening for perinatal depression and anxiety in 491 pregnant women (38). Because of the negative effects of untreated perinatal depression and anxiety on mothers and infants, it is important that at-risk women are not only identified but also treated. Fortunately, effective treatments exist for perinatal depression, although there are some limitations with regard to medications during pregnancy and lactation (39-43).

There are some limitations to our study. First, we used the EPDS rather than the clinical diagnosis of depression as the criterion measure. However, the goal of this study was to reduce the burden of screening for antenatal depression, not to diagnose major depression disorders or to examine the costs and benefits of screening, which may produce many false positives. Although a variety of measures have been used to screen women for depression and anxiety in the antenatal period, including the EPDS, the Beck Depression Inventory, the General Health Questionnaire, the Pregnancy Specific Stress Scale, and the Kessler 10 Scale of Psychological Distress, the EPDS is a good instrument that avoids misinterpreting biological symptoms that may be misconstrued as normal physiological changes associated with pregnancy (44). Another limitation of this study is the possibility that some participants may have under-reported their depressive symptoms on the screening questionnaire.

Despite such limitations, our study's strength is that it is the first to attempt simplification of a traditional screening instrument. In addition, we validated the usefulness of the newly developed simplified instrument. Based on the results of our study, we can propose its use to maternal health care providers who want to screen for antenatal depression but do not have enough time to use the full screening instrument.

Many women consider their obstetrical care provider to be their primary care provider during their childbearing years (45). Obstetrical care providers can be the usual-and sometimes only-health care providers for women during the perinatal period because pregnant women have frequent contact with them by way of prenatal visits, hospital delivery, and postpartum follow-up. The antenatal visit may provide the ideal setting in which to screen for depression because most pregnant women will get antenatal care at some point during pregnancy (46-48). Therefore, the importance of the obstetrical health care provider's role as a primary care provider who can detect depressive symptoms at an early stage should be emphasized. A major impediment to depression case identification is the difficulty in administration of depression screening in busy clinical settings. The simplified EPDS can be an efficient instrument for ruling out depression during pregnancy. And women who screen positive using the simplified EPDS should be followed up with a diagnostic interview.

\section{Acknowledgments}

We are grateful to the pregnant women who took part in this study. We also thank authors who responded to requests for information regarding statistical design and analysis.

\section{Conflict of Interest}

The authors have declared that no conflict of interest exists.

\section{References}

1. Burke KC, Burke JD, Jr., Rae DS, Regier DA. Comparing age at onset of major depression and other psychiatric disorders by birth cohorts in five US community populations. Arch Gen Psychiatry. 1991; 48: 789-95.

2. Aderibigbe YA, Gureje O, Omigbodun O. Postnatal emotional disorders in Nigerian women. A study of antecedents and associations. Br J Psychiatry. 1993; 163: 645-50.

3. Matthey S, Barnett B, Howie P, Kavanagh DJ. Diagnosing postpartum depression in mothers and fathers: whatever happened to anxiety? J Affect Disord. 2003; 74: 139-47.

4. Austin MP,Priest SR. Clinical issues in perinatal mental health: new developments in the detection and treatment of perinatal mood and anxiety disorders. Acta Psychiatr Scand. 2005; 112: 97-104.

5. Gibson J, McKenzie-McHarg K, Shakespeare J, Price J, Gray R. A systematic review of studies validating the Edinburgh Postnatal Depression Scale in antepartum and postpartum women. Acta Psychiatr Scand. 2009; 119: 350-64.

6. Bowen A, Muhajarine N. Antenatal depression. Can Nurse. 2006; 102: 26-30.

7. Figueiredo B, Pacheco A, Costa R. Depression during pregnancy and the postpartum period in adolescent and adult Portuguese mothers. Arch Womens Ment Health. 2007; 10: 103-9.

8. Bennett IM, Coco A, Coyne JC, Mitchell AJ, Nicholson J, Johnson E, Horst M, Ratcliffe S. Efficiency of a two-item pre-screen to reduce the burden of depression screening in pregnancy and postpartum: an IMPLICIT network study. J Am Board Fam Med. 2008; 21: 317-25.

9. de Tychey C, Spitz E, Briancon S, Lighezzolo J, Girvan F, Rosati A, Thockler A, Vincent S. Pre- and postnatal depression and coping: a comparative approach. J Affect Disord. 2005; 85: 323-6.

10. Limlomwongse N, Liabsuetrakul T. Cohort study of depressive moods in Thai women during late pregnancy and 6-8 weeks of postpartum using the Edinburgh Postnatal Depression Scale (EPDS). Arch Womens Ment Health. 2006; 9: 131-8. 
11. Beck CT. The effects of postpartum depression on child development: a meta-analysis. Arch Psychiatr Nurs. 1998; 12: 12-20.

12. Chung TK, Lau TK, Yip AS, Chiu HF, Lee DT. Antepartum depressive symptomatology is associated with adverse obstetric and neonatal outcomes. Psychosom Med. 2001; 63: 830-4.

13. Josefsson A, Berg G, Nordin C, Sydsjo G. Prevalence of depressive symptoms in late pregnancy and postpartum. Acta Obstet Gynecol Scand. 2001; 80: 251-5.

14. Alder J, Fink N, Bitzer J, Hosli I, Holzgreve W. Depression and anxiety during pregnancy: a risk factor for obstetric, fetal and neonatal outcome? A critical review of the literature. J Matern Fetal Neonatal Med. 2007; 20: 189-209.

15. Evans J, Heron J, Patel RR, Wiles N. Depressive symptoms during pregnancy and low birth weight at term: longitudinal study. Br J Psychiatry. 2007; 191: 84-5.

16. Glover $\mathrm{V}, \mathrm{O}^{\prime}$ Connor TG. Effects of antenatal stress and anxiety: Implications for development and psychiatry. Br J Psychiatry. 2002; 180: 389-91.

17. Suri R, Altshuler L, Hellemann G, Burt VK, Aquino A, Mintz J. Effects of antenatal depression and antidepressant treatment on gestational age at birth and risk of preterm birth. Am J Psychiatry. 2007; 164: 1206-13.

18. Field T, Diego M, Hernandez-Reif M, Schanberg S, Kuhn C, Yando R, Bendell D. Pregnancy anxiety and comorbid depression and anger: effects on the fetus and neonate. Depress Anxiety. 2003; 17: 140-51.

19. Sjostrom K, Valentin L, Thelin T, Marsal K. Maternal anxiety in late pregnancy: effect on fetal movements and fetal heart rate. Early Hum Dev. 2002; 67: 87-100.

20. Zax M, Sameroff AJ, Babigian HM. Birth outcomes in the offspring of mentally disordered women. Am J Orthopsychiatry. 1977; 47: 218-30.

21. Deave T, Heron J, Evans J, Emond A. The impact of maternal depression in pregnancy on early child development. BJOG. 2008; 115: 1043-51.

22. Bagedahl-Strindlund M,Monsen Borjesson K. Postnatal depression: a hidden illness. Acta Psychiatr Scand. 1998; 98: $272-5$.

23. Coates AO, Schaefer CA, Alexander JL. Detection of postpartum depression and anxiety in a large health plan. J Behav Health Serv Res. 2004; 31: 117-33.

24. Thio IM, Oakley Browne MA, Coverdale JH, Argyle N. Postnatal depressive symptoms go largely untreated: a probability study in urban New Zealand. Soc Psychiatry Psychiatr Epidemiol. 2006; 41: 814-8.

25. Seehusen DA, Baldwin LM, Runkle GP, Clark G. Are family physicians appropriately screening for postpartum depression? J Am Board Fam Pract. 2005; 18: 104-12.

26. Cox JL, Holden JM, Sagovsky R. Detection of postnatal depression. Development of the 10-item Edinburgh Postnatal Depression Scale. Br J Psychiatry. 1987; 150: 782-6.

27. Boyd RC, Le HN, Somberg R. Review of screening instruments for postpartum depression. Arch Womens Ment Health. 2005; 8: 141-53.

28. Eberhard-Gran M, Eskild A, Tambs K, Opjordsmoen S, Samuelsen SO. Review of validation studies of the Edinburgh Postnatal Depression Scale. Acta Psychiatr Scand. 2001; 104: 243-9.

29. Lee DT, Yip AS, Chiu HF, Leung TY, Chung TK. Screening for postnatal depression: are specific instruments mandatory? J Affect Disord. 2001; 63: 233-8.

30. Felice E, Saliba J, Grech V, Cox J. Validation of the Maltese version of the Edinburgh Postnatal Depression Scale. Arch Womens Ment Health. 2006; 9: 75-80.
31. Adewuya AO, Ola BA, Dada AO, Fasoto OO. Validation of the Edinburgh Postnatal Depression Scale as a screening tool for depression in late pregnancy among Nigerian women. J Psychosom Obstet Gynaecol. 2006; 27: 267-72.

32. Dossett EC. Perinatal depression. Obstet Gynecol Clin North Am. 2008; 35: 419-34.

33. Buist A, Bilszta J, Barnett B, Milgrom J, Ericksen J, Condon J, Hayes B, Brooks J. Recognition and management of perinatal depression in general practice--a survey of GPs and postnatal women. Aust Fam Physician. 2005; 34: 787-90.

34. Chaudron LH, Szilagyi PG, Kitzman HJ, Wadkins HI, Conwell Y. Detection of postpartum depressive symptoms by screening at well-child visits. Pediatrics. 2004; 113: 551-8.

35. Cohen LS, Nonacs R, Viguera AC, Reminick A. Diagnosis and treatment of depression during pregnancy. CNS Spectr. 2004; 9: 209-16.

36. Miranda J, Azocar F, Komaromy M, Golding JM. Unmet mental health needs of women in public-sector gynecologic clinics. Am J Obstet Gynecol. 1998; 178: 212-7.

37. Pallant JF, Miller RL, Tennant A. Evaluation of the Edinburgh Post Natal Depression Scale using Rasch analysis. BMC Psychiatry. 2006; 6: 28.

38. Goodman JH,Tyer-Viola L. Detection, treatment, and referral of perinatal depression and anxiety by obstetrical providers. J Womens Health (Larchmt). 2010; 19: 477-90.

39. Dennis CL. Preventing postpartum depression part II: A critical review of nonbiological interventions. Can J Psychiatry. 2004; 49: 526-38.

40. Hendrick V. Treatment of postnatal depression. BMJ. 2003; 327: 1003-4.

41. O'Hara MW, Stuart S, Gorman LL, Wenzel A. Efficacy of interpersonal psychotherapy for postpartum depression. Arch Gen Psychiatry. 2000; 57: 1039-45.

42. Pearlstein T. Perinatal depression: treatment options and dilemmas. J Psychiatry Neurosci. 2008; 33: 302-18.

43. Spinelli MG,Endicott J. Controlled clinical trial of interpersonal psychotherapy versus parenting education program for depressed pregnant women. Am J Psychiatry. 2003; 160: 555-62.

44. Fernandes MC, Srinivasan K, Stein AL, Menezes G, Sumithra RS, Ramchandani PG. Assessing prenatal depression in the rural developing world: a comparison of two screening measures. Arch Womens Ment Health. 2011; 14: 209-16.

45. Scholle SH, Haskett RF, Hanusa BH, Pincus HA, Kupfer DJ. Addressing depression in obstetrics/gynecology practice. Gen Hosp Psychiatry. 2003; 25: 83-90.

46. Coleman VH, Carter MM, Morgan MA, Schulkin J. Obstetrician-gynecologists' screening patterns for anxiety during pregnancy. Depress Anxiety. 2008; 25: 114-23.

47. Marcus SM, Flynn HA, Blow FC, Barry KL. Depressive symptoms among pregnant women screened in obstetrics settings. J Womens Health (Larchmt). 2003; 12: 373-80.

48. Weissman MM, Feder A, Pilowsky DJ, Olfson M, Fuentes M, Blanco C, Lantigua R, Gameroff MJ, Shea S. Depressed mothers coming to primary care: maternal reports of problems with their children. J Affect Disord. 2004; 78: 93-100. 